\title{
Melatonin ameliorates cognitive memory by regulation of cAMP-response element-binding protein expression and the anti-inflammatory response in a rat model of post-traumatic stress disorder
}

Bombi Lee ${ }^{1,2^{*}} \mathbb{C}$, Insop Shim ${ }^{1,3}$, Hyejung Lee ${ }^{1}$ and Dae-Hyun Hahm ${ }^{1,2^{*}}$

\begin{abstract}
Background: Post-traumatic stress disorder (PTSD) is an important psychological disease that can develop following the physical experience or witnessing of traumatic events. The psychopathological response to traumatic stressors increases inflammation in the hippocampus and induces memory deficits. Melatonin (MTG) plays critical roles in circadian rhythm disorders, Alzheimer's disease, and other neurological disorders. However, the cognitive efficiency of MTG and its mechanisms of action in the treatment of PTSD remain unclear. Thus, the present study investigated the effects of MTG on spatial cognitive impairments stimulated by single prolonged stress (SPS) in rats, an animal model of PTSD. Male rats received intraperitoneal (i.p.) administration of various doses of MTG for 21 consecutive days after the SPS procedure.
\end{abstract}

Results: SPS-stimulated cognitive impairments in the object recognition task and Morris water maze were reversed by MTG treatment ( $25 \mathrm{mg} / \mathrm{kg}$, i.p). Additionally, MTG significantly increased cognitive memory-related decreases in cAMP-response element-binding (CREB) protein and mRNA levels in the hippocampus. Our results also demonstrate that MTG significantly inhibited SPS-stimulated cognitive memory impairments by inhibiting the expression of proinflammatory cytokines, including tumor necrosis factor-a (TNF-a), and interleukin-6 (IL-6) in the rat brain.

Conclusion: The present results indicate that MTG can be beneficial for SPS-stimulated memory impairments via changes in CREB expression and proinflammatory mediators. Thus, MTG may be a prophylactic strategy for the prevention or mitigation of the progression of some features of the PTSD pathology.

Keywords: Melatonin, Memory, Post-traumatic stress disorder, cAMP-response element-binding protein, Proinflammatory cytokines

\footnotetext{
*Correspondence: bombi@khu.ac.kr; dhhahm@khu.ac.kr

${ }^{1}$ Acupuncture and Meridian Science Research Center, College of Korean

Medicine, Kyung Hee University, 26, Kyungheedae-ro, Dongdaemun-gu,

Seoul 02447, Republic of Korea

Full list of author information is available at the end of the article
}

(c) The Author(s) 2018. This article is distributed under the terms of the Creative Commons Attribution 4.0 International License (http://creativecommons.org/licenses/by/4.0/), which permits unrestricted use, distribution, and reproduction in any medium, provided you give appropriate credit to the original author(s) and the source, provide a link to the Creative Commons license, and indicate if changes were made. The Creative Commons Public Domain Dedication waiver (http://creativecommons.org/ publicdomain/zero/1.0/) applies to the data made available in this article, unless otherwise stated. 


\section{Background}

Declarative memory dysfunction is related to post-traumatic stress disorder (PTSD), which manifests following exposure to severe trauma [1]. In humans, early traumatic experiences and adversity significantly enhance one's vulnerability to various psychiatric disorders, including memory impairment and PTSD, in adulthood [2]. The psychopathological conditions in response to traumatic stressors are caused by intrusive memories in which individuals re-experience the original traumatic experience, avoid trauma-associated events, have unpleasant recollections, avoid associated events, and exhibit negative cognition/mood, hyperarousal, and marked social impairments [3, 4]. Moreover, the persistent occurrence of extremely repulsive memory associated with the trauma and an incapacity to dissipate these fear memory are major characteristics of this disease [5]. PTSD patients also exhibit significant cognitive deficits, including damaged declarative and working memory abilities and impairments in attention and concentration [6-8]. Furthermore, cognitive impairments and memory dysfunction continually appear in conjunction with the development of PTSD [5]. The cognitive deficits observed in PTSD patients have been hypothesized to be the result of unpleasant flashback memories that temporarily interfere with the capability to procedure new memories or information [9-11]. For instance, placing a rat in a context in which it has been shocked impairs memory on an entirely different test $[7,11]$, such as the localization of a hidden platform in a water maze.

Single prolonged stress (SPS) is a well-validated animal model of PTSD [12]. Several studies have suggest that animals exposed to SPS exhibit states that mimic human mental disorders, including enhanced anxiety, impaired fear extinction, changes in hypothalamic-pituitary-adrenal (HPA) axis function [13], and increased cytokines in the hippocampus [14]. The hippocampus, which plays an major role in cognition and memory, is particularly vulnerability to neuronal damage caused by SPS $[5,15]$. Furthermore, this damage can subsequently result in impairments in spatial learning and memory and synaptic plasticity $[15,16]$.

A recent study discovered that hippocampal volume is reduced in patients with PTSD [17], which emphasizes the association between stress and the loss of hippocampus neurons. In hippocampus brain-derived neurotrophic factor (BDNF) and cAMP-response element-binding protein (CREB) play major roles in pathological responses of the central nervous system (CNS) and have been related to PTSD $[5,18]$. Furthermore, the hippocampus is susceptible to the inflammatory response to traumatic stress, which disrupts neuronal circuitry [19, 20], is associated with the psychosocial stress of PTSD, and alters the protein and gene expression of inflammatory mediators [21].

Currently, selective serotonin reuptake inhibitors (SSRIs) are an important mediator of the progression of PTSD and are used as potential pharmacological interventions [22, 23]. However, the used of SSRIs is contentious due to their continually reported side effects and their associated poor patient compliance [24]. Thus, there is a critical need for a novel therapeutic strategy for the treatment of PTSD [25].

Melatonin ( $N$-acetyl-5-methoxytryptamine, MTG) is the major hormone released by the pineal gland at night and is secreted into the cerebrospinal fluid and circulation [26]. This neurohormone plays a important role in the modulation of the biological clock, specifically the sleep-wake cycle and the induction of physiological sleep $[26,27]$. MTG plays numerous physiological roles as a regulator of circadian rhythms, a protector of mitochondria, an anti-inflammatory, an antioxidant, and a neuroprotectant agent [28-32]. The beneficial effects of MTG on neurological diseases have been widely investigated. Additionally, MTG is also thought to be involved in the modulation of complex processes, such as learning and memory [33, 34], via its binding to receptors widely distributed throughout the brain [35]. For instance, MTG in rats promotes memory in the novel object recognition task [ORT; 36, 37] and the olfactory social memory test [38]. The exogenous administration of MTG results in neuroprotective effects $[39,40]$ and enhance cognitive capacity [41]. MTG may exert particular therapeutic effects in patients with Alzheimer disease (AD) and Parkinson's disease [PD; 42, 43] by protecting against neurotoxicity induced by beta-amyloid $(\mathrm{A} \beta)$ peptides [44, 45]. For example, MTG supplementation may weakens A $\beta$ accumulation, inflammation, neurodegeneration, and memory impairments in $\mathrm{AD}$ patients and an animal model of AD [32, 41, 46]. Therefore, MTG and its receptor agonists are considered prospective therapeutic agents for $\mathrm{AD}$ treatment [32, 41, 46]. Additionally, some studies have shown that MTG attenuates pyramidal neuronal cell damage in the hippocampus in global cerebral ischemia [47-50]. The neuroprotective effects of MTG are related to inhibited oxidative stress and neuroinflammation [51, 52].

Based on such findings, MTG was hypothesized to alleviate SPS-stimulated memory impairment as measured by an ORT and the Morris water maze (MWM) test. Additionally, the possible mechanisms underlying the neuroprotective effects of MTG were assessed in a rat model of PTSD, and the relationships between stress-stimulated cognition and memory impairment and BDNF and CREB expressions and inflammation in the hippocampus region were evaluated. The present 
findings will contribute to the development of novel approaches to the treatment of trauma- and stressrelated disorders, including PTSD.

\section{Methods}

\section{Animals and MTG administration}

Eight-week male SD rats weighing 200-230 g were obtained from Samtaco Animal Co. (Osan, South Korea). The vivarium room was kept on a 12-h light/ dark cycle (lights on at 8:00, lights off at 20:00) under relative humidity of $55 \pm 15 \%$ and a controlled temperature at $22 \pm 2{ }^{\circ} \mathrm{C}$. All rats were caged for 7 days to acclimatize before beginning the experimental protocol. Ethics approval was obtained from Kyung Hee University's Institutional Animal Care and Use Committee (KHUASP(SE)-15-115). All experimental procedures were performed according to the Guide for the Care and Use of Laboratory Animals.

MTG $(5,10$ and $25 \mathrm{mg} / \mathrm{kg}$, body weight, SigmaAldrich Chemical Co. St. Louise, MO, USA) and fluoxetine for positive drug $(10 \mathrm{mg} / \mathrm{kg}$, FLX, fluoxetine hydrochloride; Sigma) were applied by intraperitoneally (i.p.) after the exposure to SPS for 21 days. The standard doses and period of MTG used in the this study was applied on other study $[53,54]$. MTG and FLX were liquefied in $0.9 \%$ saline before use.

The rats were randomly divided into six groups of six to seven individuals each as follows: the saline-treated group (CON group, $\mathrm{n}=7$ ), the SPS-stimulated plus saline-treated group (SPS group as a control, $\mathrm{n}=7$ ), the SPS-stimulated plus $5 \mathrm{mg} / \mathrm{kg}$ MTG-treated group (SPS+MTG5 group, $\mathrm{n}=6$ ), the SPS-stimulated plus $10 \mathrm{mg} / \mathrm{kg}$ MTG-treated group (SPS+MTG10 group, $\mathrm{n}=6$ ), the SPS-stimulated plus $20 \mathrm{mg} / \mathrm{kg}$ MTG-treated group (SPS + MTG20 group, $\mathrm{n}=7$ ) and the SPSstimulated plus $10 \mathrm{mg} / \mathrm{kg}$ fluoxetine-treated group (SPS + FLX group, $\mathrm{n}=7$ ). The entire experimental schedules are shown in the Fig. 1.

\section{Single prolonged stress}

Rat were exposed to SPS for 14 successive days as described by Patki's group with a slight modification [55, 56]. Briefly, rats were restrained for $2 \mathrm{~h}$ on a holder and then promptly placed in a forced swimming condition for $20 \mathrm{~min}$. The rats were allowed to dry and recuperate for $15 \mathrm{~min}$ and then exposed to ether vapor until loss of consciousness. Following the SPS procedure, rats were housed one per cage and left undisturbed for 14 days to allow PTSD-like symptoms to become apparent [55]. The other half of the rats for control group were momentarily placed in a separate area of the room during the SPS procedure. All rats were returned to the vivarium room and housed for 14 days without disturbance other.

\section{Object recognition task}

The novel ORT was used to estimate the cognitive capability of rats. This test was essentially the same as that described by Okuda et al. [57]. Briefly, the equipment was consists square wood box and painted with black $\left(45 \times 45 \times 45 \mathrm{~cm}^{3}\right)$. The objects in the equipment is prepared a familiar objects and a novel object. The familiar objects (A1 and A2) to be discriminated were two similar toys as due to make objects enough heavy, so that rats could not be able to move objects. The novel object (B) was different shape and different color toy. On habituate, the rats were adapted to the object recognition box during $10 \mathrm{~min}$. The test phase was started $24 \mathrm{~h}$ after the habituation. Rats were exposed inside the equipment with two familiar objects during $5 \mathrm{~min}$. During the test phase, rats housed to the testing chamber, where rats were exposed to one novel object (B) and one of the familiar object during $5 \mathrm{~min}$. The exploration (sniffing) time for the novel and familiar objects is measured. The discrimination index is calculated of discrimination between the familiar and the novel object accurate for exploration. It is expressed as: (time spent on novel object-time spent on familiar object)/(time spent on novel object + time spent on familiar object).

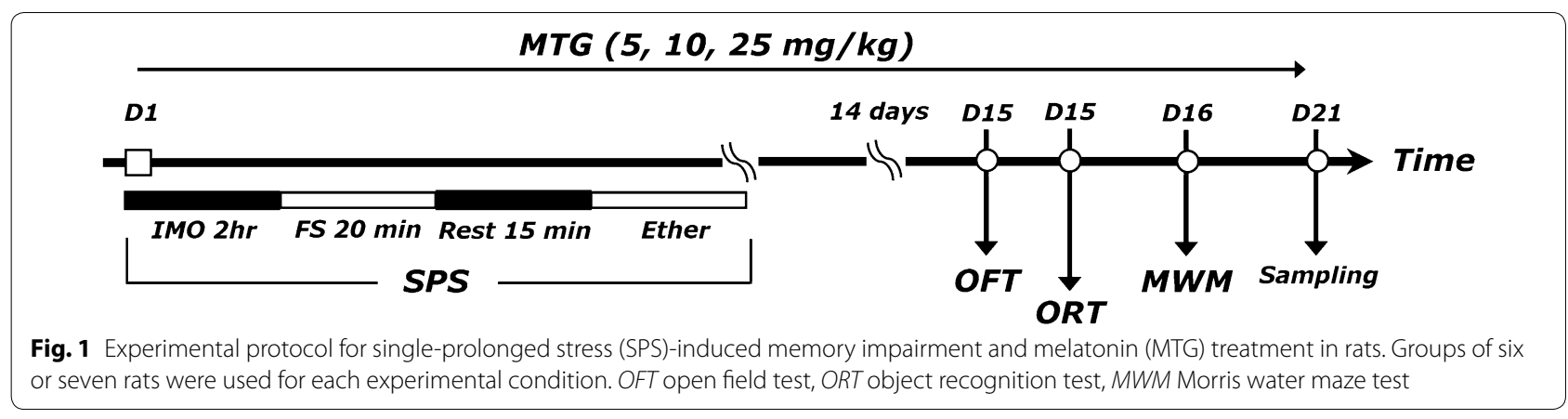




\section{Morris water maze test}

After the ORT, the MWM test was used to measure the time and distance spent swimming to reach a submerged platform in the MWM test, performed as previously described [58]. MWM test was made of a spatial probe test and a place navigation test. The MWM consisted of a circular pool $(200 \mathrm{~cm}$ diameter and $50 \mathrm{~cm}$ deep). The pool contained water maintained at a temperature of $22 \pm 2{ }^{\circ} \mathrm{C}$. The escape platform $(15 \mathrm{~cm}$ diameter $)$ in diameter was located $1.5 \mathrm{~cm}$ below the water in one of four sections of the pool. The hidden platform trial for acquisition test and probe trails for retention test were monitored by a video camera mounted on the ceiling, and data were analyzed by using a tracking program (S-MART: PanLab Co., Barcelona, Spain). The rats performed three training trials per day for five successively days. Each trial was terminated when the rat found the platform or after $180 \mathrm{~s}$. On day 6 , the platform was removed. In this probe trial, the each trial was $1 \mathrm{~min}$ in duration. The swimming path length, swimming speed, and time spent in the target quadrant were analyzed.

\section{Open field test (OFT)}

Before the completion of the MWM test, the rats were exposed to the OFT. The OFT was carried out according to a previously described method [55]. In the dimly lit room, rats was exposed singly in a square black plexiglass apparatus $(60 \times 60 \times 30 \mathrm{~cm})$ and tracked by a video tracking system for $5 \mathrm{~min}$. Locomotion were analyzed by the distance and speed of movements and observed by a computerized video-tracking analysis program S-MART (PanLab Co., Barcelona, Spain). The number of rearing was also manually scored by examining the records in the OFT.

\section{Measurement of corticosterone (CORT), BDNF, CREB and proinflammatory markers}

All rats were deeply anesthetized through inhalation of isoflurane (1.2\%) and were humanely sacrificed 1 day after behavioral measurement. The concentration of CORT, tumor necrosis factor- $\alpha$ (TNF- $\alpha)$, and interleukin-6 (IL-6) in the blood, and BDNF and CREB in the brain 21 days after SPS have been described previously [58]. The blood ( $n=4 /$ group) was rapidly collected via the abdominal aorta. The hippocampus ( $n=4 /$ group) was quickly removed from the rat brain in a randomized order. The CORT, TNF- $\alpha$, IL-6, BDNF and CREB concentrations were measured by a competitive enzyme-linked immunosorbent assay (ELISA) using a CORT antibody (Novus Biologicals, LLC., Littleton, CO, USA), a TNF- $\alpha$ antibody (Abcam, Cambridge, MA, USA), an IL-6 antibody (Abcam), a BDNF antibody (R\&D Systems, Minneapolis, MN, USA), and a CREB antibody (Thermo
Fisher Scientific, Waltham, MA, USA) according to the manufacturer's protocol. Detectable CORT (46-304 ng/ $\mathrm{mL})$, BDNF (9-45 pg/mg), CREB (1-62 pg/mg), TNF- $\alpha$ (4-52 pg/mL), and IL-6 (1-54 pg/mL) concentrations ranged. Intra-assay and inter assay variation ranged from 1.35-10.31\% CV and 4.73-16.59\% CV, respectively. 100\% specificity to rat CORT, BDNF, CREB, TNF- $\alpha$ and IL-6 were reported in manufacturer protocol.

\section{Total RNA preparation and RT-PCR analysis}

The expression of BDNF, CREB, TNF- $\alpha$ and IL- 6 mRNA was evaluated by reverse transcription-polymerase chain reaction (RT-PCR) according to a previously described method [58]. In brief, total RNA was extracted from the hippocampus ( $n=3$ /group) of each rat using TRIzol reagent (Life Technologies, Carlsbad, CA, USA) according to the manufacturer's instructions. cDNA was synthesized from $2 \mu \mathrm{g}$ total RNA using reverse transcriptase (Takara Bio, Otsu, Japan) with random hexamers (COSMO Genetech, Seoul, Korea), and then amplified at $57{ }^{\circ} \mathrm{C}$ for 27 cycles in the BDNF reaction, at $51{ }^{\circ} \mathrm{C}$ for 27 cycles in the CREB reaction, at $58{ }^{\circ} \mathrm{C}$ for 30 cycles in the TNF- $\alpha$ reaction, and at $60{ }^{\circ} \mathrm{C}$ for 30 cycles in the IL- 6 reaction by PCR using Taq DNA polymerase (Takara, Kyoto, Japan) on a thermal cycler. Data were normalized against GADPH expression in the corresponding sample.

\section{Immunohistochemistry}

The immunohistochemical analyses have been described previously [58]. The sections obtained from the brains were immunostained for CREB expression using the avidin-biotin-peroxidase complex (ABC) method. Briefly, the sections were incubated with a primary rabbit antiCREB antibody (1:200 dilution, Cell Signaling, Boston, MA, USA) in PBS plus $0.3 \%$ Triton X-100 (PBST) for $72 \mathrm{~h}$ at $4{ }^{\circ} \mathrm{C}$. Next, the sections were incubated for $120 \mathrm{~min}$ at room temperature with secondary antibodies (1:200 dilution, Vector Laboratories Co., Burlingame, CA, USA) in PBST containing $2 \%$ normal serum. To visualize immunoreactivity, the sections were incubated for $90 \mathrm{~min}$ in $\mathrm{ABC}$ reagent (Vectastain Elite $\mathrm{ABC}$ kit, Vector Labs. Co.), and then in a solution containing 3,3'-diaminobenzidine (DAB; Sigma-Aldrich) and $0.01 \% \mathrm{H}_{2} \mathrm{O}_{2}$ for $1 \mathrm{~min}$. The sections were viewed at $200 \times$ magnification, and the number of CREB-labeled cells was quantified in the hippocampus.

\section{Statistical analysis}

All data are expressed as mean \pm SEM. The data were analyzed with SPSS 13.0 (Chicago, IL, USA). Data were analyzed by the multiple way of analysis of variance (ANOVA) and Tukey's post hoc tests. Between-subjects two-way ANOVA was used to analyze the effects of MTG 
treatment and time. In all of the analyses, differences were considered statistically significant at $p<0.05$.

\section{Results \\ Effect of MTG on SPS-stimulated changes in the plasma CORT level}

ELISA analysis showed that rats who underwent SPS exposure had a significantly higher plasma CORT concentration $(297.87 \%)$ than rats in the saline-treated $(\mathrm{CON})$ group 21 days after SPS exposure $(p<0.05$; Fig. 2$)$. However, administration of MTG at $25 \mathrm{mg} / \mathrm{kg}$ decreased the SPS-stimulated increase in the plasma CORT level $(p<0.05)$. However, administration of MTG at 5 or $10 \mathrm{mg} / \mathrm{kg}$ did not alter plasma CORT levels in the SPSpretreated rats. Thus, the SPS procedure caused memory impairments in rats and was utilized to develop the PTSD or traumatic stress model in rats. The increased plasma CORT concentration in the SPS group was significantly replaced to levels similar to those in the CON group by $10 \mathrm{mg}$ FLX $(p<0.05)$. This reversal display that the CORT concentration in the plasma of rats treating $25 \mathrm{mg} / \mathrm{kg}$ MTG was similar to that of rats treating $10 \mathrm{mg} / \mathrm{kg}$ FLX. Suppression of the increase in plasma CORT level by

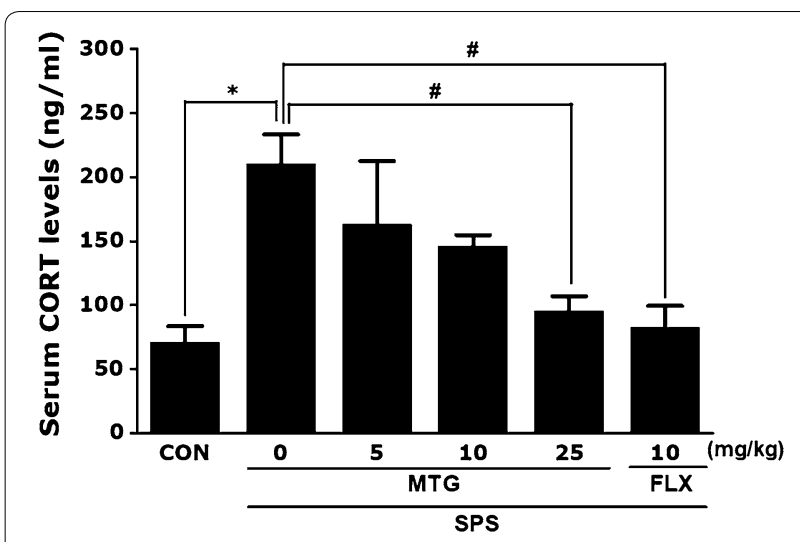

Fig. 2 Effects of MTG on plasma corticosterone (CORT) levels in rats with SPS-induced memory impairments: assessed with an enzyme-linked immunosorbent assay (ELISA). Parameters were determined at the end of the experiments. Data are expressed as the mean \pm SEM of 4 animals in each group. ${ }^{*} p<0.05$ versus the CON group; $" p<0.05$ versus the SPS group
MTG also provided a base for the scientific inference that SPS-induces memory impairment in rats.

\section{Effects of MTG on SPS-stimulated memory impairment}

The novel object recognition for learning and memory function was indicated by means of the exploration (sniffing) times of familiar and novel objects and by computation of the discrimination indix by the ORT (Fig. 3a and b). Analyses of sniffing times for old objects by one-way ANOVA revealed no significant differences between the groups $(\mathrm{F}(5,39)=1.857, p=0.128)$. There was no significant difference among the groups in sniffing time for old objects. Analyses of sniffing times for novel objects by one-way ANOVA revealed significant differences between groups $(\mathrm{F}(5,39)=37.059, p<0.001)$, and post hoc comparisons using Tukey's test manifested a significant reduction in sniffing time for novel objects in all SPS-stimulated groups compared to the sniffing time in controls $(p<0.001$; Fig. 3a). The negative effect of stress on recognition memory, indicated by sniffing time, was altered by MTG treatment ( 5 and $10 \mathrm{mg} / \mathrm{kg}$ ). There were no statistically significant effects of MTG (5 and $10 \mathrm{mg} /$ $\mathrm{kg}$ ) treatment on the remaining parameters measured in the ORT. However, the rats in the SPS + MTG25 group indicated longer sniffing times for novel objects than the rats in the SPS group $(p<0.001)$. Post-hoc examination with Tukey test revealed that the discrimination index of PTSD group was significantly reduced compared to the CON group $(p<0.05$; Fig. $3 \mathrm{~b})$. However, the rats in the SPS + MTG25 group indicated a higher discrimination index than the rats in the SPS group $(p<0.05)$. This difference also showed that the recovery of recognition memory after the SPS stimulated deficit was almost comparable in the SPS + MTG25 and the SPS + FLX groups.

In MWM test, SPS-stimulated rats were weak to learn during acquisition trial and retention trial. The effects of MTG treatment on swimming time to reach the submerged platform in the MWM test are shown in Fig. 3cf. The SPS group indicated marked retardation in escape latency during all trial sessions, especially due to memory impairments resulting from SPS-stimulated learning and memory deficits.

PTSD influenced performance in the acquisition phase. More specifically, the SPS group indicated

(See figure on next page.)

Fig. 3 Effects of MTG on recognition memory assessed by the novel object recognition test (ORT) in which the time spent sniffing familiar and novel objects during a 3-min choice trial (a) and the ability to discriminate (b) between familiar and novel objects were measured. The Morris water maze (MWM) test was used to assess the effects of MTG on spatial learning and memory. Time to escape (latency) from the water onto a submerged platform during acquisition trials (c), percentages of time spent in the target quadrant (d), percentages of distance traversed in the target quadrant (e), and swimming speed (f) were used as outcome measures. The open field test (OFT) was used to assess the effect of MTG on locomotor activity (counts) and total number of rearing bouts $(\mathbf{g})$. Six or seven rats were used per treatment group. Data are represented as the mean \pm SEM. ${ }^{*} p<0.05,{ }^{* *} p<0.01,{ }^{* *} p<0.001$ versus the CON group; ${ }^{\#} p<0.05,{ }^{\# \#} p<0.01,{ }^{\# \# \#} p<0.001$ versus the SPS group 


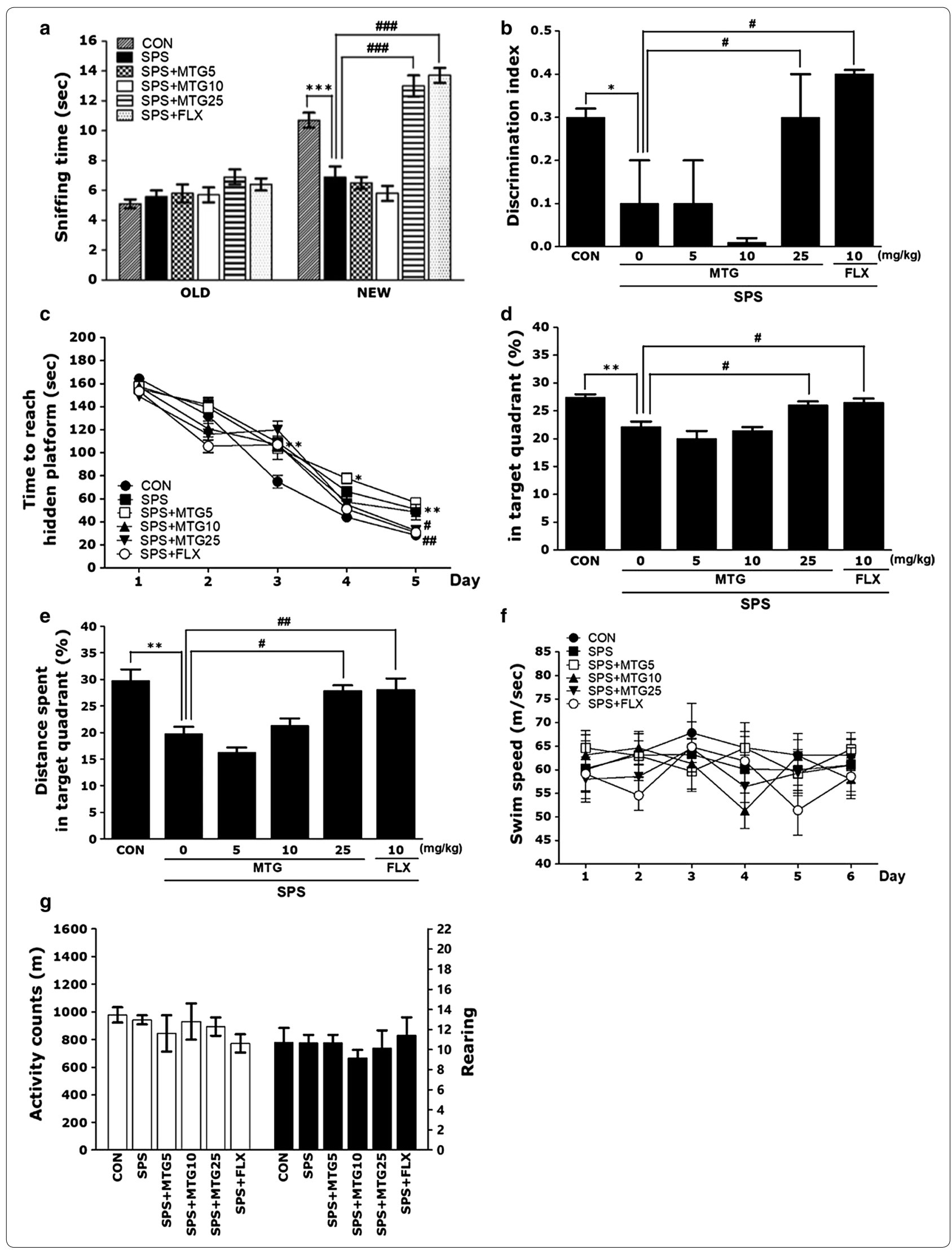


significantly enhanced latency compared with the CON group (Fig. 3c, d). ANOVA $(6 \times 5$, treatment $\times$ time) disclosed a significant difference among groups $(\mathrm{F}(5,34)=16.240, \quad p<0.01)$ and an effect of the day of training $(\mathrm{F}(4136)=351.639, p<0.01)$; however, a group $\times$ day interaction was not discovered $(\mathrm{F}(20,136)=1.588, p=0.064)$. The SPS group indicated worse performance than the CON group $(p<0.05$ on the days 3 and $5, p<0.01$ on the day 4$)$. Tukey's post hoc test showed that rats in the SPS+MTG25 group had significantly reduced swimming latency compared to those in the SPS group ( $p<0.01$ on day 5 ). Both the 5 and $10 \mathrm{mg} / \mathrm{kg}$ MTG treatment groups still exhibited longer swimming durations than the SPS group. To examine the effect of SPS and MTG on the spatial memory of rats, performance in the probe trial on day 6 was investigated by calculating the percentages of time spent swimming in the speculated position of the platform. The swimming times and distances were reduced in the rats that swam directly to the target area where the platform had been located. The rats exposed to SPS indicated serious deficits of spatial memory performance in the MWM test $(p<0.01$; Fig. $3 \mathrm{~d}$, e). A reduction in distance traveled was observed when $10 \mathrm{mg} / \mathrm{kg}$ MTG was administered to rats exposed to SPS, although this result was only marginally significant. Therefore, $10 \mathrm{mg} / \mathrm{kg}$ MTG could not completely restore the impaired memory in SPS rats. The rats in the $25 \mathrm{mg} / \mathrm{kg}$ MTG-treated group spent more time around the platform area than those in the SPS group $(p<0.05)$. Furthermore, the swimming latency in rats that received MTG was higher than the latency in the SPS group, indicating a reversal of the SPS-stimulated impairment in memory. Thus, MTG-treated rats indicated a significant improvement in the memory retention test because they spent more time in the quadrant where the platform was previously located and swam over the previous location of the platform more continually. The SPS group was not significantly different from the other groups in mean swimming speed, as analyzed by dividing the total swim distance by latency $(p=0.645$; Fig. 3f). Based on these results, rats treated with $25 \mathrm{mg} / \mathrm{kg}$ MTG indicated greater enhancement in acquisition during the hidden platform trial and, consequently, arrived the platform more quicker than the SPS-stimulated rats. Our results also showed that the swimming latency of the SPS-stimulated rats treating $25 \mathrm{mg} / \mathrm{kg}$ MTG was similar to that of rats treating $10 \mathrm{mg} / \mathrm{kg}$ of FLX.

A parametric one-way ANOVA was executed, and as shown in Fig. 3g, no PTSD-associated differences were discovered in locomotor activity (motor function) or total number of rearings (hyperactivity) in the OFT. There was no significant difference between saline-treated rats, SPS-exposed rats, and MTG-treated rats in remarked locomotor activity $(\mathrm{F}(5,39)=1.271$, $p=0.322)$ or total number of rearings $(\mathrm{F}(5,39)=0.337$, $p=0.887$ ).

Because no significant difference in locomotor activity was remarked among groups in the OFT, the remarked deficits in learning and memory in the rats exposed to SPS were not attributable to differences in locomotor activity. Rats may also indicate water-avoidance behaviors when tackled with an MWM test. However, this results demonstrate that no rats presented anxiety-like behaviors in the OFT after a stress exposure in the MWM test.

\section{Effects of MTG on SPS-stimulated changes in BDNF and CREB in the hippocampus}

Figure 4 indicates that the hippocampal levels of BDNF and CREB were significantly different among the groups. One-way ANOVA of the concentrations of BDNF and CREB in the hippocampus disclosed a significant difference among the groups $[(\mathrm{F}(5,23)=3.961, p<0.05)$ and $((\mathrm{F}(5,23)=6.133, p<0.01)$. The post hoc test results showed a significant decline in BDNF and CREB concentrations in the hippocampus of the SPS group compared with those in the CON group $(p<0.05$; Fig. 4$)$. Furthermore, $10 \mathrm{mg} / \mathrm{kg}$ MTG could not completely reverse the decreased concentration of hippocampal BDNF and CREB observed in the SPS group. Daily administration of $25 \mathrm{mg} / \mathrm{kg}$ MTG reversed the SPS-stimulated decrease in BDNF level in the hippocampus, although this result was only marginally significant. Daily administration of $25 \mathrm{mg} / \mathrm{kg}$ MTG significantly reversed the SPS-stimulated decrease in CREB concentration in the hippocampus $(p<0.05)$. Additionally, the CREB concentration in the hippocampus of rats treating $10 \mathrm{mg} / \mathrm{kg}$ FLX was similar to that in the hippocampus of rats treating $25 \mathrm{mg} / \mathrm{kg}$ MTG.

To further investigate the effects of MTG on the expression of neurotrophic factors in the hippocampus of rats exposed to SPS, BDNF and CREB mRNA expression was analyzed by RT-PCR. Although the mRNA level of BDBF in the SPS group was lower than that in the CON group, this result was only marginally significant. However, CREB mRNA expression in the SPS group was significantly lower than that in the CON group $(p<0.01)$. The decreased expression of CREB mRNA in the SPS group was significantly reinstated to levels similar to those in the CON group by $25 \mathrm{mg} / \mathrm{kg}$ MTG $(p<0.01)$. Furthermore, CREB mRNA expression in the hippocampus of rats treating $25 \mathrm{mg} / \mathrm{kg}$ MTG was similar to that of rats treating $10 \mathrm{mg} / \mathrm{kg}$ FLX. 

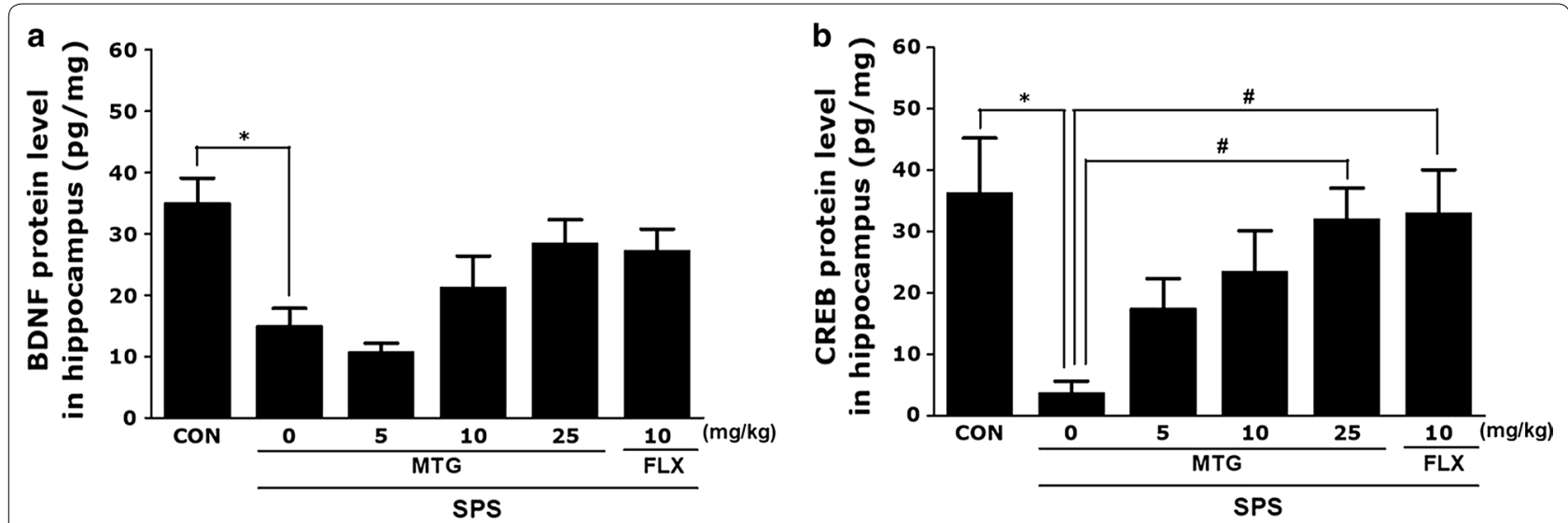

c
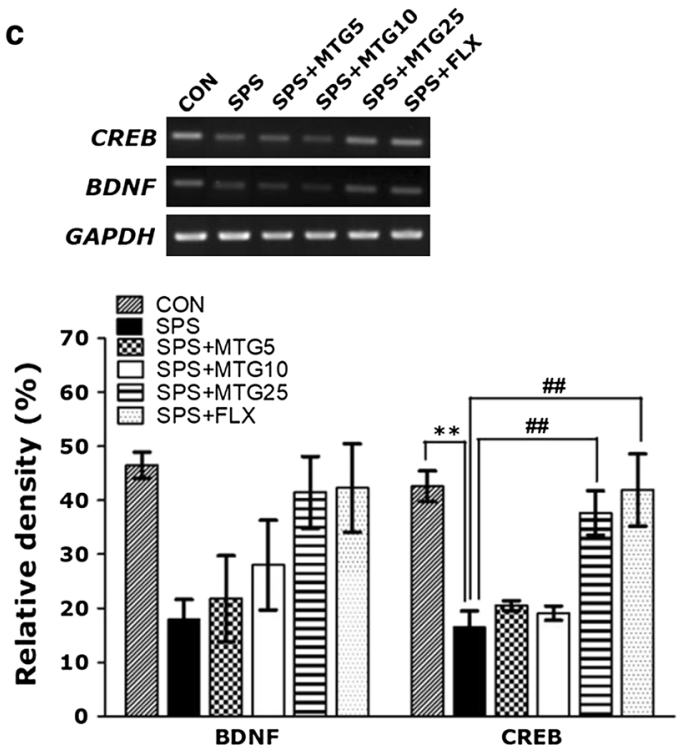

Fig. 4 Effects of MTG on brain-derived neurotrophic factor (BDNF) and CAMP-response element-binding (CREB) protein levels (a and $\mathbf{b})$ and BDNF and CREB mRNA expression in the hippocampus of rats with SPS-induced memory impairments. Polymerase chain reaction (PCR) bands on agarose gels and relative intensities (c). BDNF and CREB mRNA expression was normalized to the expression of glyceraldehyde 3-phosphate dehydrogenase $(\mathrm{GAPDH}) \mathrm{mRNA}$ as an internal control. Parameters were determined at the end of the experiments. Data are expressed as the mean \pm SEM of 4 animals in each group. ${ }^{*} p<0.05,{ }^{* *} p<0.01$ versus the CON group; ${ }^{*} p<0.05,{ }^{\# \#} p<0.01$ versus the SPS group

\section{Effects of MTG on SPS-stimulated changes} in neuroinflammatory cytokines in the hippocampus

Figure 5 indicates that the hippocampal concentrations of TNF- $\alpha$ and IL- 6 were significantly different in comparisons among the groups. One-way ANOVA of the concentrations of TNF- $\alpha$ and IL- 6 in the hippocampus disclosed a significant difference among the groups $((\mathrm{F}(5,23)=4.678, p<0.01)$ and $((\mathrm{F}(5,23)=4.189$, $p<0.05)$. The post hoc test results showed a significant increase in TNF- $\alpha$ and IL- 6 levels in the hippocampus of the SPS groups compared to those in the CON group $(p<0.05$ and $p<0.01$; Fig. 5). Furthermore, MTG (5 and $10 \mathrm{mg} / \mathrm{kg}$ ) treatment could not completely reverse the increased concentration of hippocampal TNF- $\alpha$ or
IL-6 observed in the SPS group. However, daily administration of $25 \mathrm{mg} / \mathrm{kg}$ MTG significantly reversed the SPS-stimulated increase in the TNF- $\alpha$ level in the hippocampus $(p<0.05)$, and daily treatment of $25 \mathrm{mg} / \mathrm{kg}$ MTG reversed the SPS-stimulated increase in IL-6 in the hippocampus, although this result was only marginally significant. Additionally, the TNF- $\alpha$ concentration in the hippocampus of rats treating $10 \mathrm{mg} / \mathrm{kg}$ FLX was similar to that of rats treating $25 \mathrm{mg} / \mathrm{kg}$ MTG.

To investigate the effects of MTG on the expression of neuroinflammatory cytokines in the hippocampus of rats exposed to SPS, the mRNA expression of TNF- $\alpha$ and IL- 6 was analyzed by RT-PCR. The mRNA levels of TNF- $\alpha$ and IL-6 in the SPS group were significantly 

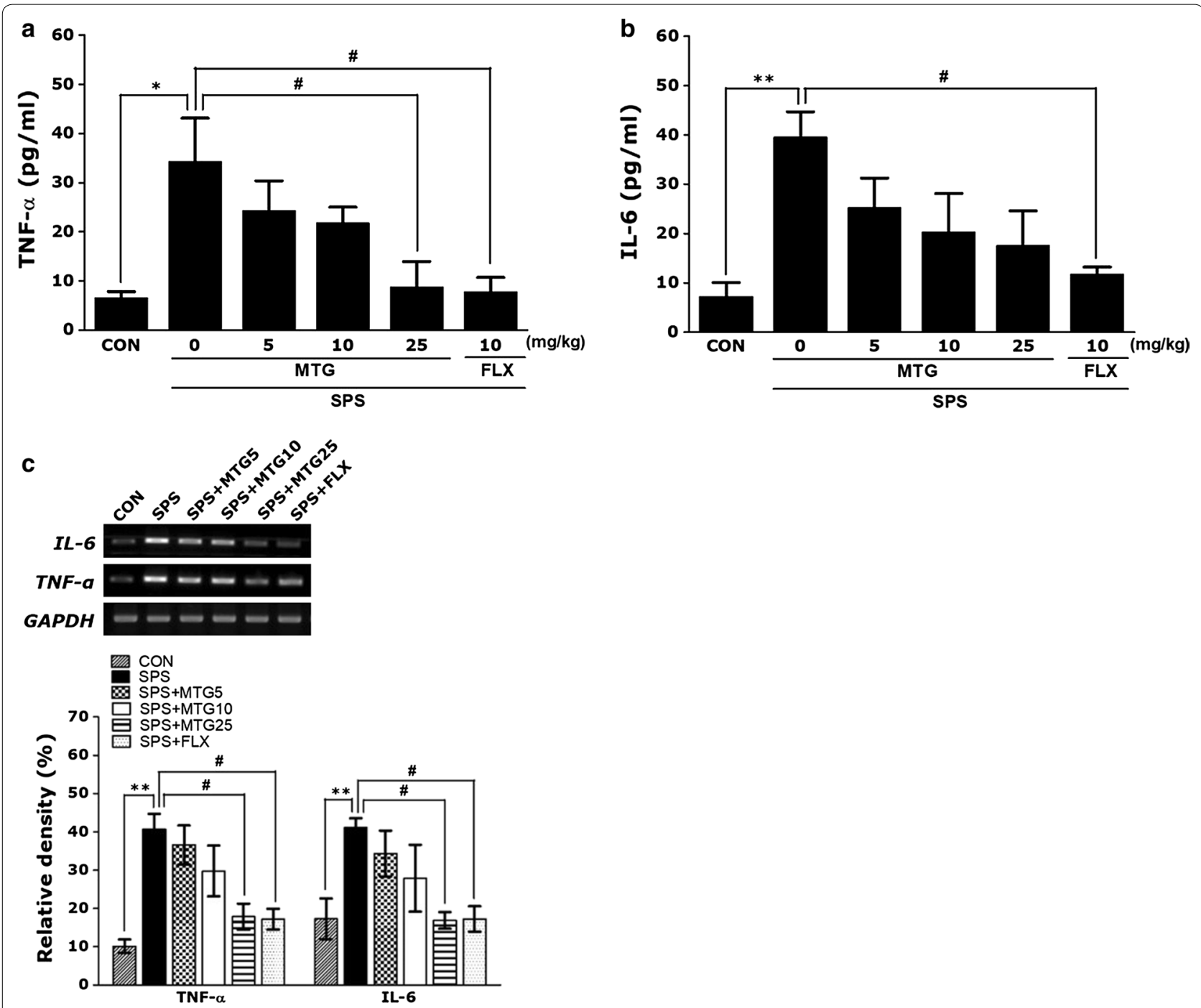

Fig. 5 Effects of MTG on tumor necrosis factor-a (TNF-a) and interleukin-6 (IL-6) protein levels (a and $\mathbf{b}$ ) and TNF-a and IL-6 mRNA expression in the hippocampus of rats with SPS-induced memory impairments. PCR bands on agarose gels and relative intensities (c). TNF- $a$ and IL-6 mRNA levels were normalized to GAPDH levels as an internal control. Parameters were determined at the end of the experiments. Data are expressed as the mean \pm SEM of 4 animals in each group. ${ }^{*} p<0.05,{ }^{* *} p<0.01$ versus the CON group; ${ }^{*} p<0.05$ versus the SPS group

increased compared with that in the $\mathrm{CON}$ group $(p<0.01)$, but the increased TNF- $\alpha$ and IL-6 mRNA expression in the SPS group was significantly reinstated to levels similar to those in the CON group by $25 \mathrm{mg} / \mathrm{kg}$ MTG $(p<0.05)$. Finally, TNF- $\alpha$ and IL-6 mRNA expression in the hippocampus of rats treating $25 \mathrm{mg} / \mathrm{kg}$ MTG was similar to that of rats treating $10 \mathrm{mg} / \mathrm{kg}$ FLX.

\section{Effect of MTG on SPS-stimulated changes in CREB in the hippocampus}

Following the behavioral tests, brain tissue from the rats were analyzed using immunohistochemistry to examine the effect of MTG treatment on the neuronal loss related to the SPS-stimulated memory deficits. The quantification of CREB immunoreactive cells in the hippocampus are shown in Fig. 6. In the SPS group, the number of CREB-immunoreactive neurons in the CA1 and CA3 of the hippocampus was decreased to 60.86 and $68.66 \%$ relative to those in the $\mathrm{CON}$ group, respectively. One-way ANOVA of the number of CREB immunoreactive cells disclosed a significant difference among the six groups $((5,95)=3.868, p<0.01)$ and $((5,95)=3.735, p<0.01)$. Post hoc comparisons showed that CREB reaction in the hippocampus of the SPS group was significantly lower than that of the CON group $(p<0.01$ in the CA1 and $p<0.05$ in the CA3). The number of CREB-immunoreactive 


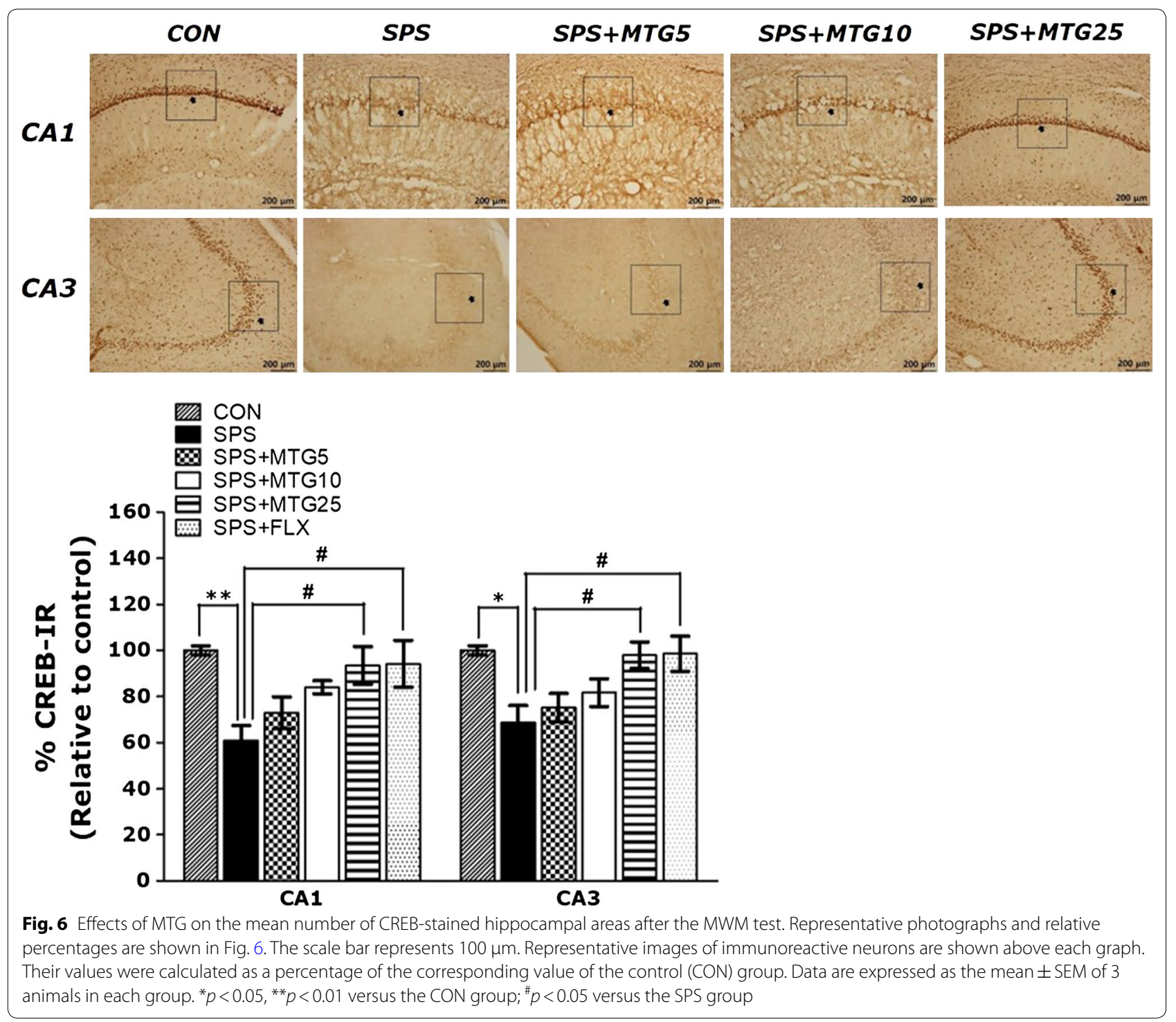

neurons in the SPS + MTG25 group was significantly higher in the CA1 and CA3 of the hippocampal region than in those of the SPS group $(p<0.05)$. This results also showed that the number of CREB-activity neuronal cells in the hippocampus in rats treating $25 \mathrm{mg} / \mathrm{kg}$ MTG was similar to that in rats treating $10 \mathrm{mg} / \mathrm{kg}$ FLX.

\section{Discussion}

The present results demonstrated that SPS-stimulated memory impairments were associated with serious impairment in performance on tests of learning and memory function as well as corresponding signs of neurodegeneration in the brain, including decreased BDNF and CREB expression and increased proinflammatory cytokine levels in the hippocampus. However, treatment with MTG in a rat model of PTSD significantly advanced cognitive functions on the ORT and enhanced the number of platform crossings in the MWM test. Additionally, MTG treatment enhanced CREB activities in the hippocampus of male rats exposed to SPS-stimulated memory impairments and inhibited the increase in proinflammatory mediators in the hippocampus of rats with SPS-stimulated PTSD symptoms.

The SPS procedure is a well-validated animal model of PTSD with high face validity that addresses the core etiological factors of this disorder, including maladaptive cognitive processes, altered neuroplasticity, and enhanced negative feedback in the HPA axis [13]. SPS in rats transiently produces several impairment in 
learning acquisition and short-term memory that are associated with be similar to PTSD or chronic stress $[12,13]$. Therefore, in the present study, rats were subjected to SPS to mimic the psychosocial and physiological stressors associated with PTSD and then treated with various doses of MTG.

In this model, the compulsory sustaining of high CORT levels affects cognition by decreasing memory ability, which may be associated with the progression or exacerbation of traumatic stress in humans [55]. The SPS procedure increased the plasma CORT level in the rats, which is in line with chronic stress models. In rat models, compulsory maintenance of high CORT levels can affect cognition by decreasing memory ability under experimental conditions and might be closely correlated with the progression or exacerbation of a chronically stressful condition in humans [55]. The HPA axis is an important component of the neuroendocrine system that controls immune function, energy expenditure, emotions and mood, and stress [59]. HPA axis dysfunction is a specific neuroendocrine role in experimental animals and humans with PTSD [59].

MTG is the primary secretory product of the pineal gland $[60,61]$. The secretion of MTG with the circadian rhythm in the blood of mammals is functionally linked to the adjustment of 24-h cycles and to circannual rhythm control. The opposing circadian alternation in MTG and HPA-related hormones may suggest a connection between these two factors. MTG has been showed to be able to reverse HPA-axis activity caused by stress, which is similar to this results [61,62]. In addition, MTG has also been showed to cause an inhibitory effect on both stimulated and spontaneous HPA axis activation [63]. Stress stimulates the HPA axis and influences several biological effects at both the peripheral and central level. In the present study, MTG treatment after application of the SPS procedure significantly reduced serum CORT levels and improved the behavioral alternations stimulated by SPS. Our results showed that the SPS procedure produced severe impairment in the performance of cognitive functioning tests and decreases in BDNF and CREB expression in the hippocampus, suggestive of neurodegeneration in the brain. MTG restored plasma CORT to near normal levels toward the end of the 2-week treatment period, which suggests that this treatment inhibited stress-related dysfunction in the HPA axis, alleviated associated behavioral diseases, and increased CREB expression and anti-inflammatory activity. Thus, the present findings indicate that MTG treatment prevented the dysfunction of the HPA axis. These findings may elucidate the mechanisms underlying the effects of MTG in the hippocampus as well as the biochemical and behavioral signals caused by low plasma levels of CORT.
The ORT and MWM test were used to investigate the effects of MTG on cognitive memory and spatial learning and memory, respectively, and the present findings showing that SPS impaired recognition memory are consistent with those of a previous study [16]. Cognitive impairments were significantly more pronounced after exposure to SPS, as indicated by a significant enhance in time spent exploring familiar objects, reduced exploration of novel objects, and a reduction in the discrimination index. These findings suggest that, following exposure to memory-impairing agents, there is a profound deterioration in the brain that contributes to a diminished episodic memory and recognition capacity [58]. Accordingly, the this study showed that SPS significantly reduced time spent sniffing novel objects and reduced the discrimination index, whereas treatment with MTG significantly enhanced time spent sniffing novel objects and improved recognition memory. The present study used the MWM test because it is more useful for assessing spatial learning and memory in rats than other conventional mazes, such as the radial-arm maze and T-maze [58]. The MWM is a hippocampus-associated memory test that is frequently used to investigate cognitive impairment and study constant spatial learning and memory abilities and reference memory in rats [64]. In the present study, the chronically stressed animals had a significantly longer escape latency to reach the platform than the non-stressed animals and exhibited spatial learning deficits in the MWM test. The chronically stressed animals that received MTG learned faster and had shorter escape latency than the untreated chronic stress group. Moreover, compared with the nonstressed rats, the chronically stressed rats that did not receive MTG treatment exhibited poorer performances on probe trials administered $24 \mathrm{~h}$ after task acquisition, which is indicative of damaged memory recall and retrieval. MTG reversed these behavioral abnormalities and reinstated spatial learning and memory in the chronically stressed rats. A similar effect was seen following chronic treatment with fluoxetine [65]. Thus, the this findings support and prove the hypothesis that MTG ameliorates spatial learning and memory impairment caused by traumatic stress.

An OFT was performed to rule out the potentially confounding effects of motor deficits, which could influence the outcomes of behavioral tests of anxiety and depression. However, no significant individual differences in locomotor activity were discovered between the groups, which suggests that MTG treatment did not affect sensorimotor performance. Thus, the improved performance in the MWM test was more likely due to improved learning and memory than to differences in limb flexibility, motor output, or sensorimotor function. Furthermore, no rats in either group appeared 
anxiety-like behaviors in the OFT after stress exposure in the MWM test, which indicates that MTG did not alter psychomotor function or active responses as measured by performance in the MWM test.

To identify additional MTG-related mechanisms underlying the improvements in memory, the effects of MTG on BDNF and CREB levels in the hippocampus were investigated. The change in the levels of BDNF and CREB proteins in the brain supplies a novel treatment strategy for the amelioration of memory impairment [66]. In addition to its roles in neuronal cell survival and the prevention of neurodegeneration, recent experimental evidence strongly supports the role of BDNF in the regulation of synaptic function and plasticity in the CNS for learning and memory processes [67]. However, in the present study, no significant individual differences in BDNF level were observed following treatment with MTG, which suggests that MTG did not affect the BDNF level. CREB is also believed to play a critical role in the formation of memories [66]. SPSstimulated memory impairment are associated with significant reductions in CREB mRNA expression in the hippocampus as well as poor performance on hippocampus-dependent tests $[5,65]$. In the present study, MTG treatment significantly reversed SPS-stimulated decreases in CREB mRNA expression, which suggests that the beneficial effects of MTG were mediated by increases in CREB expression that may be associated with enhanced neuronal function and performance in learning and memory tests. Furthermore, the present findings indicate that there is a correlation between protein and gene function and decreased CREB expression in the hippocampus.

Additionally, the current results also strongly suggest a close correlation between hippocampal CREB expression and number of CREB-immunoreactive neurons in the hippocampus. CREB dysfunction interrupts hippocampus-dependent memory formation, and CREB has been suggested to be required for memory solidity [68, 69]. Thus, BDNF transcriptional activity, up-regulated by CREB, may also play an important role in adaptive neuronal activations underlying memory function [70, 71]. The administration of MTG is proposed to significantly prevent the reduction in CREB in the hippocampus stimulated by SPS exposure, leading to memory deficits. Although MTG reversed the decrease in CREB expression in the hippocampus to some degree, the effect of MTG on other upstream or downstream pathways involving CREB was not determined [72]. The changes in CREB associated with memory impairment have been found to be accompanied by enhances in the phosphorylation of extracellular signal-related kinase [72]. Thus, further studies will be necessary to clarify more precisely the effects of MTG on the CREB-mediated signaling pathway.

In the present study, SPS also significantly increased the expression of TNF- $\alpha$ and IL- 6 in the hippocampus, which ultimately led to a chronic neuroinflammatory activation in the brain. Many studies have demonstrated that SPSstimulated TNF- $\alpha$ and IL- $1 \beta$ expression are upregulated in PTSD and that these cytokines play a role in several events associated with the pathological cascade of PTSD [73]. Thus, inflammatory reactions may be associated with the pathogenesis of degenerative changes as well as cognitive impairments [74]. In this study, SPS induced an increase in the levels of the proinflammatory cytokines TNF- $\alpha$ and IL- 6 and produced learning and memory impairment. However, MTG inhibited the increased expression of TNF- $\alpha$ and IL- 6 in SPS-treated rats. MTG decreased the SPS-stimulated increase in the mRNA expression of TNF- $\alpha$ and IL-6, eventually resulting in the reversal of chronic inflammation and the amelioration of persistent brain dysfunction [65, 73]. According to the inflammation hypothesis, memory impairments in PTSD are due to selective and irreversible dysfunction and chronic inflammation in the brain $[65,73]$. Thus, the anti-inflammatory effects of MTG are proposed here to significantly reverse the impaired memory retention and the increased expression of proinflammatory cytokines.

\section{Conclusions}

In summary, the present study demonstrated that SPS impaired neuronal function and produced associated memory and cognitive impairment in a rat model of progressive memory impairment in neurodegenerative disease. This was evidenced by performance on the ORT and MWM tests and by protein and gene expression analyses of CREB and BDNF. However, MTG treatment significantly attenuated the SPS-stimulated deficits as indicated by improved cognitive function on the behavioral tests, increased CREB expression, and normalization of the HPA axis. Moreover, MTG suppressed increases in the mRNA expressions of TNF- $\alpha$ and IL-6, which are proinflammatory mediators, in the hippocampus. Thus, MTG may be a useful agent for the prevention of neuronal impairments and the attenuation of anti-inflammatory effects such as those observed in patients with PTSD.

\section{Abbreviations}

PTSD: Post-traumatic stress disorder; MTG: Melatonin; SPS: Single prolonged stress; CREB: CAMP-response element-binding protein; HPA: Hypothalamicpituitary-adrenal; BDNF: Brain-derived neurotrophic factor; SSRIs: Selective reuptake inhibitors; AD: Alzheimer disease; PD: Parkinson's disease; ORT: Object recognition task; MWM: Morris water maze; SD: Sprague-Dawley; FLX: Fluoxetine; CORT: Corticosterone; OFT: Open field test; TNF-a: Tumor necrosis factor-a; IL-6: Interleukin-6; ELISA: Enzyme-linked immunoassay; RT-PCR: 
Reverse transcription-polymerase chain reaction; GAPDH: Glyceraldehyde3-phosphate dehydrogenase; PBS: Phosphate-buffered saline; ABC: Avidinbiotin-peroxidase complex; DAB: 3,3'-Diaminobenzidine; ANOVA: Analysis of variance.

\section{Authors' contributions}

BL performed most experiments, data analysis and wrote the first draft of the paper. BL participated in animal experiments including behavioral tests. $\mathrm{DHH}$ directed the study, contributed to the discussion, edited and approved the manuscript. IS helped with concept development and data analysis. $\mathrm{HL}$ contributed to data analysis, wrote and revised the manuscript. All authors read and approved the final manuscript.

\section{Author details}

${ }^{1}$ Acupuncture and Meridian Science Research Center, College of Korean Medicine, Kyung Hee University, 26, Kyungheedae-ro, Dongdaemun-gu, Seoul 02447, Republic of Korea. ${ }^{2}$ Center for Converging Humanities, Kyung Hee University, Seoul 02447, Republic of Korea. ${ }^{3}$ Department of Physiology, College of Medicine, Kyung Hee University, Seoul 02447, Republic of Korea.

\section{Acknowledgements}

This research was supported by a Grant from the National Research Foundation of Korea funded by the Korean government (2016R1D1A1A09917012).

\section{Competing interests}

The authors declared that they have no competing interests.

\section{Availability of data and materials}

All data supporting the conclusions of this article are included within the article. The datasets used /or analysed during the current study available from the corresponding author on reasonable request.

\section{Consent for publication}

Not applicable.

\section{Ethics approval and consent to participate}

This investigation does not involve human subject. All animal experiments and surgical procedures were approved by the ethical guidelines of the Animal Care and Use Committee of Kyung Hee University (KHUASP(SE)-15-115), on the use of animals for scientific research. All efforts were made to minimize the number of animals used and their suffering.

\section{Publisher's Note}

Springer Nature remains neutral with regard to jurisdictional claims in published maps and institutional affiliations.

Received: 7 August 2017 Accepted: 28 June 2018

Published online: 04 July 2018

\section{References}

1. Lu CY, Liu X, Jiang H, Pan F, Ho CS, Ho RC. Effects of traumatic stress induced in the juvenile period on the expression of gamma-aminobutyric acid receptor type A subunits in adult rat brain. Neural Plast. 2017;2017:5715816.

2. Anda RF, Felitti VJ, Bremner JD, Walker JD, Whitfield C, Perry BD, Dube SR, Giles $\mathrm{WH}$. The enduring effects of abuse and related adverse experiences in childhood. A convergence of evidence from neurobiology and epidemiology. Eur Arch Psychiatry Clin Neurosci. 2006;256(3):174-86.

3. Brunello N, Davidson JR, Deahl M, Kessler RC, Mendlewicz J, Racagni G, Shalev AY, Zohar J. Posttraumatic stress disorder: diagnosis and epidemiology, comorbidity and social consequences, biology and treatment. Neuropsychobiology. 2001;43(3):150-62.

4. Nemeroff CB, Bremner JD, Foa EB, Mayberg HS, North CS, Stein MB. Post traumatic stress disorder: a state-of-the-science review. J Psychiatr Res. 2006;40(1):1-21.

5. Shafia S, Vafaei AA, Samaei SA, Bandegi AR, Rafiei A, Valadan R, HosseiniKhah Z, Mohammadkhani R, Rashidy-Pour A. Effects of moderate treadmill exercise and fluoxetine on behavioural and cognitive deficits, hypothalamic-pituitary-adrenal axis dysfunction and alternations in hippocampal BDNF and mRNA expression of apoptosis-related proteins in a rat model of post-traumatic stress disorder. Neurobiol Learn Mem. 2017;139(1):165-78.

6. Buckley TC, Blanchard EB, Neill WT. Information processing and PTSD: a review of the empirical literature. Clin Psychol Rev. 2000;20(8):1041-65.

7. Burke HM, Robinson CM, Wentz B, McKay J, Dexter KW, Pisansky JM, Talbot JN, Zoladz PR. Sex-specific impairment of spatial memory in rats following a reminder of predator stress. Stress. 2013;16(4):469-76.

8. Gilbertson MW, Gurvits TV, Lasko NB, Orr SP, Pitman RK. Multivariate assessment of explicit memory function in combat veterans with posttraumatic stress disorder. J Trauma Stress. 2001;14(1):413-32.

9. Brewin CR, Smart L. Working memory capacity and suppression of intrusive thoughts. J Behav Ther Exp Psychiatry. 2005;36(1):61-8.

10. McNally RJ. Debunking myths about trauma and memory. Can J Psychiatry. 2005;50(1):817-22.

11. Zoladz PR, Woodson JC, Haynes VF, Diamond DM. Activation of a remote (1-year old) emotional memory interferes with the retrieval of a newly formed hippocampus-dependent memory in rats. Stress. 2010;13(1):36-52

12. Serova LI, Laukova M, Alaluf LG, Pucillo L, Sabban EL. Intranasal neuropeptide $Y$ reverses anxiety and depressive-like behavior impaired by single prolonged stress PTSD model. Eur Neuropsychopharmacol. 2014;24(1):142-7.

13. Yamamoto S, Morinobu S, Takei S, Fuchikami M, Matsuki A, Yamawaki S, Liberzon I. Single prolonged stress: toward an animal model of posttraumatic stress disorder. Depress Anxiety. 2009;26(12):1110-7.

14. Serova LI, Laukova M, Alaluf LG, Sabban EL. Intranasal infusion of melanocortin receptor four (MC4R) antagonist to rats ameliorates development of depression and anxiety related symptoms induced by single prolonged stress. Behav Brain Res. 2013;250(1):139-47.

15. Lin CC, Tung CS, Lin PH, Huang CL, Liu YP. Traumatic stress causes distinctive effects on fear circuit catecholamines and the fear extinction profile in a rodent model of posttraumatic stress disorder. Eur Neuropsychopharmacol. 2016;26(9):1484-95.

16. Li XM, Han F, Liu DJ, Shi YX. Single-prolonged stress induced mitochondrial-dependent apoptosis in hippocampus in the rat model of posttraumatic stress disorder. J Chem Neuroanat. 2010;40(3):248-55.

17. Li X, Han F, Liu D, Shi Y. Changes of Bax, BCl-2 and apoptosis in hippocampus in the rat model of post-traumatic stress disorder. Neurol Res. 2010;32(6):579-86.

18. Takei S, Morinobu S, Yamamoto S, Fuchikami M, Matsumoto T, Yamawaki S. Enhanced hippocampal BDNF/TrkB signaling in response to fear conditioning in an animal model of posttraumatic stress disorder. J Psychiatr Res. 2011;45(4):460-8.

19. Loganovsky KN, Zdanevich NA. Cerebral basis of posttraumatic stress disorder following the Chernobyl disaster. CNS Spectr. 2013;8(2):95-102.

20. Ragu Varman D, Rajan KE. Environmental enrichment reduces anxiety by differentially activating serotonergic and neuropeptide Y (NPY)-Ergic System in Indian field mouse (Mus booduga): an animal model of posttraumatic stress disorder. PLoS ONE. 2015;10(5):e0127945.

21. Ebenezer PJ, Wilson CB, Wilson LD, Nair AR, J F. The anti-inflammatory effects of blueberries in an animal model of post-traumatic stress disorder (PTSD). PLoS ONE. 2016;11(9):e0160923.

22. Han F, Xiao B, Wen L, Shi Y. Effects of fluoxetine on the amygdala and the hippocampus after administration of a single prolonged stress to male Wistar rates: in vivo proton magnetic resonance spectroscopy findings. Psychiatry Res. 2015;232(2):154-61.

23. Schoenfeld FB, Marmar CR, Neylan TC. Current concepts in pharmacotherapy for posttraumatic stress disorder. Psychiatr Serv. 2004;55(5):519-31.

24. Penn E, Tracy DK. The drugs don't work? Antidepressants and the current and future pharmacological management of depression. Ther Adv Psychopharmacol. 2012;2(5):179-88.

25. Liberzon I, López JF, Flagel SB, Vázquez DM, Young EA. Differential regulation of hippocampal glucocorticoid receptors mRNA and fast feedback: relevance to post-traumatic stress disorder. J Neuroendocrinol. 1999;11(1):11-7.

26. Fu W, Xie H, Laudon M, Zhou S, Tian S, You Y. Piromelatine ameliorates memory deficits associated with chronic mild stress-induced anhedonia in rats. Psychopharmacology. 2016;233(12):2229-39. 
27. Sharif R, Aghsami M, Gharghabi M, Sanati M, Khorshidahmad T, Vakilzadeh G, Mehdizadeh H, Gholizadeh S, Taghizadeh G, Sharifzadeh M. Melatonin reverses $\mathrm{H}-89$ induced spatial memory deficit: involvement of oxidative stress and mitochondrial function. Behav Brain Res. 2017;316(1):115-24.

28. Hardeland R, Cardinali DP, Brown GM, Pandi-Perumal SR. Melatonin and brain inflammaging. Prog Neurobiol. 2017;217-128(1):46-63.

29. Manchester LC, Coto-Montes A, Boga JA, Andersen LP, Zhou Z, Galano A, Vriend J, Tan DX, Reiter RJ. Melatonin: an ancient molecule that makes oxygen metabolically tolerable. J Pineal Res. 2015;59(4):403-19.

30. Moretti R, Zanin A, Pansiot J, Spiri D, Manganozzi L, Kratzer I, Favero G, Vasiljevic A, Rinaldi VE, Pic I, Massano D, D'Agostino I, Baburamani A, La Rocca MA, Rodella LF, Rezzani R, Ek J, Strazielle N, Ghersi-Egea JF, Gressens P, Titomanlio L. Melatonin reduces excitotoxic blood-brain barrier breakdown in neonatal rats. Neuroscience. 2015;311(1):382-97.

31. Rudnitskaya EA, Muraleva NA, Maksimova KY, Kiseleva E, Kolosova NG, Stefanova NA. Melatonin attenuates memory impairment, amyloid- $\beta$ accumulation, and neurodegeneration in a rat model of sporadic alzheimer's disease. J Alzheimers Dis. 2015;47(1):103-16.

32. Zhang $S$, Wang $P$, Ren $L, H u C, B i$ J. Protective effect of melatonin on soluble A 1 1-42-induced memory impairment, astrogliosis, and synaptic dysfunction via the Musashi1/Notch1/Hes1 signaling pathway in the rat hippocampus. Alzheimers Res Ther. 2016;8(1):40-5.

33. Huang F, Yang Z, Liu X, Li CQ. Melatonin facilitates extinction, but not acquisition or expression, of conditional cued fear in rats. BMC Neurosci. 2014;15(1):86-91.

34. Rawashdeh O, Maronde E. The hormonal Zeitgeber melatonin: role as a circadian modulator in memory processing. Front Mol Neurosci. 2012;5(1):27-31.

35. Morgan PJ, Barrett P, Howell HE, Helliwell R. Melatonin receptors: localization, molecular pharmacology and physiological significance. Neurochem Int. 1994:24(2):101-46.

36. Bertaina-Anglade V, Drieu-La-Rochelle C, Mocaër E, Seguin L. Memory facilitating effects of agomelatine in the novel object recognition memory paradigm in the rat. Pharmacol Biochem Behav. 2011;98(4):511-7.

37. He P, Ouyang $X$, Zhou S, Yin W, Tang C, Laudon M, Tian S. A novel melatonin agonist Neu-P11 facilitates memory performance and improves cognitive impairment in a rat model of Alzheimer' disease. Horm Behav. 2013;64(1):1-7.

38. Argyriou A, Prast H, Philippu A. Melatonin facilitates short-term memory. Eur J Pharmacol. 1998;349(2-3):159-62.

39. Barceló P, Nicolau C, Gamundí A, Fiol MA, Tresguerres JA, Akaârir M, Rial RV. Comparing the behavioural effects of exogenous growth hormone and melatonin in young and old Wistar rats. Oxid Med Cell Longev. 2016;2016:5863402.

40. Pandi-Perumal SR, BaHammam AS, Brown GM, Spence DW, Bharti VK, Kaur C, Hardeland R, Cardinali DP. Melatonin antioxidative defense: therapeutical implications for aging and neurodegenerative processes. Neurotox Res. 2013;23(3):267-300.

41. Furio AM, Brusco LI, Cardinali DP. Possible therapeutic value of melatonin in mild cognitive impairment: a retrospective study. J Pineal Res. 2007:43(4):404-9.

42. Esteban S, Nicolaus C, Garmundi A, Rial RV, Rodríguez AB, Ortega E, Ibars CB. Effect of orally administered L-tryptophan on serotonin, melatonin, and the innate immune response in the rat. Mol Cell Biochem. 2004:267(1-2):39-46.

43. Rosales-Corral SA, Acuña-Castroviejo D, Coto-Montes A, Boga JA, Manchester LC, Fuentes-Broto L, Korkmaz A, Ma S, Tan DX, Reiter RJ. Alzheimer's disease: pathological mechanisms and the beneficial role of melatonin. J Pineal Res. 2012;52(2):167-202.

44. Mukda S, Panmanee J, Boontem P, Govitrapong P. Melatonin administration reverses the alteration of amyloid precursor protein-cleaving secretases expression in aged mouse hippocampus. Neurosci Lett. 2016;621(1):39-46.

45. Rudnitskaya EA, Maksimova KY, Muraleva NA, Logvinov SV, Yanshole LV, Kolosova NG, Stefanova NA. Beneficial effects of melatonin in a rat model of sporadic Alzheimer's disease. Biogerontology. 2015;16(3):303-16.

46. Cardinali DP, Vigo DE, Olivar N, Vidal MF, Furio AM, Brusco LI. Therapeutic application of melatonin in mild cognitive impairment. Am J Neurodegener Dis. 2012;3:280-91.
47. Lee $\mathrm{CH}$, Park JH, Ahn JH, Won MH. Effects of melatonin on cognitive impairment and hippocampal neuronal damage in a rat model of chronic cerebral hypoperfusion. Exp Ther Med. 2016;11(6):2240-6.

48. Lee CH, Yoo KY, Choi JH, Park OK, Hwang IK, Kwon YG, Kim YM, Won $\mathrm{MH}$. Melatonin's protective action against ischemic neuronal damage is associated with up-regulation of the MT2 melatonin receptor. J Neurosci Res. 2010;88(12):2630-40

49. Lee EJ, Lee MY, Chen HY, Hsu YS, Wu TS, Chen ST, Chang GL. Melatonin attenuates gray and white matter damage in a mouse model of transient focal cerebral ischemia. J Pineal Res. 2005;38(1):42-52.

50. Letechipía-Vallejo G, López-Loezab E, Espinoza-González V, González-Burgos I, Olvera-Cortés ME, Moralí G, Cervantes M. Long-term morphological and functional evaluation of the neuroprotective effects of post-ischemic treatment with melatonin in rats. J Pineal Res. 2007;42(2):138-46.

51. Lee MY, Kuan YH, Chen HY, Chen TY, Chen ST, Huang CC, Yang IP, Hsu YS, Wu TS, Lee EJ. Intravenous administration of melatonin reduces the intracerebral cellular inflammatory response following transient focal cerebral ischemia in rats. J Pineal Res. 2007;42(3):297-309.

52. Tyagi E, Agrawal R, Nath C, Shukla R. Effect of melatonin on neuroinflammation and acetylcholinesterase activity induced by LPS in rat brain. Eur J Pharmacol. 2010;640(1-3):206-10.

53. Keskin-Aktan A, Akbulut KG, Yazici-Mutlu C, Sonugur G, Ocal M, Akbulut $\mathrm{H}$. The effects of melatonin and curcumin on the expression of SIRT2, BCl-2 and Bax in the hippocampus of adult rats. Brain Res Bull. 2018:137:306-10

54. Rebai R, Jasmin L, Boudah $A$. The antidepressant effect of melatonin and fluoxetine in diabetic rats is associated with a reduction of the oxidative stress in the prefrontal and hippocampal cortices. Brain Res Bull. 2017:134:142-50

55. Lee B, Sur B, Cho SG, Yeom M, Shim I, Lee H, Hahm DH. Ginsenoside Rb1 rescues anxiety-like responses in a rat model of post-traumatic stress disorder. J Nat Med. 2016;70(2):133-44.

56. Patki G, Li L, Allam F, Solanki N, Dao AT, Alkadhi K, Salim S. Moderate treadmill exercise rescues anxiety and depression-like behavior as well as memory impairment in a rat model of posttraumatic stress disorder. Physiol Behav. 2014;130(1):47-53.

57. Okuda S, Roozendaal B, McGaugh JL. Glucocorticoid effects on object recognition memory require training-associated emotional arousal. Proc Natl Acad Sci USA. 2004;101(3):853-8.

58. Lee B, Sur B, Cho SG, Yeom M, Shim I, Lee H, Hahm DH. Wogonin attenuates hippocampal neuronal loss and cognitive dysfunction in trimethyltin-intoxicated rats. Biomol Ther. 2016;24(3):328-37.

59. Kim BK, Seo JH. Treadmill exercise alleviates post-traumatic stress disorder-induced impairment of spatial learning memory in rats. J Exerc Rehabil. 2013;9(4):413-9.

60. Tan DX, Manchester LC, Hardeland R, Lopez-Burillo S, Mayo JC, Sainz RM, Reiter RJ. Melatonin: a hormone, a tissue factor, an autocoid, a paracoid, and an antioxidant vitamin. J Pineal Res. 2003;34:75-8.

61. Zhang L, Guo HL, Zhang HQ, XU TQ, He B, Wang ZH, Yang YP, Tang XD, Zhang P, Liu FE. Melatonin prevents sleep deprivation-associated anxietylike behavior in rats: role of oxidative stress and balance between GABAergic and glutamatergic transmission. Am J Transl Res. 2017;9(5):2231-42.

62. Saito S, Tachibana T, Choi YH, Denbow DM, Furuse M. ICV melatonin reduces acute stress responses in neonatal chicks. Behav Brain Res. 2005;165:197-203.

63. Giordano R, Pellegrino M, Picu A, Bonelli L, Balbo M, Berardelli R, Lanfranco F, Ghigo E, Arvat E. Neuroregulation of the hypothalamus-pituitary-adrenal (HPA) axis in humans: effects of GABA-, mineralocorticoid-, and GH-Secretagogue-receptor modulation. Sci World J. 2006;6:1-11.

64. Janasson Z. Meta-analysis of sex differences in rodent models of learning and memory: a review of behavioral and biological data. Neurosci Biobehav Rev. 2005:28(8):811-25.

65. Lee B, Sur B, Yeom M, Shim I, Lee H, Hahm DH. Effects of systemic administration of ibuprofen on stress response in a rat model of post-traumatic stress disorder. Korean J Physiol Pharmacol. 2016;20(4):357-66.

66. Tyagi E, Agrawal R, Zhuang Y, Abad C, Waschek JA, Gomez-Pinilla F. Vulnerability imposed by diet and brain trauma for anxiety-like phenotype: implications for post-traumatic stress disorders. PLOS ONE. 2013;8(3):e57945 
67. Bollen E, Vanmierlo T, Akkerman S, Wouters C, Steinbusch HM, Prickaerts J. 7,8-Dihydroxyflavone improves memory consolidation processes in rats and mice. Behav Brain Res. 2013;257(1):8-12.

68. Saura CA, Valero J. The role of CREB signaling in Alzheimer's disease and other cognitive disorders. Rev Neurosci. 2011;22(2):153-69.

69. Pittenger C, Huang YY, Paletzki RF, Bourtchouladze R, Scanlin H, Vronskaya $S$, Kandel ER. Reversible inhibition of CREB/ATF transcription factors in region CA1 of the dorsal hippocampus disrupts hippocampus-dependent spatial memory. Neuron. 2002;34(3):447-62.

70. Vaynman S, Ying Z, Gomez-Pinilla F. Interplay between brain-derived neurotrophic factor and signal transduction modulators in the regulation of the effects of exercise on synaptic-plasticity. Neuroscience. 2003;122(3):647-57
71. Tyler WJ, Alonso M, Bramham CR, Pozzo-miller LD. From acquisition to consolidation: on the role of brain-derived neurotrophic factor signaling in hippocampal-dependent learning. Learn Mem. 2002;9(5):224-37.

72. Rang OhS, Jin Kim S, Hyun Kim D, Hoon Ryu J, Ahn EM, Wook Jung J. Angelica keiskei ameliorates scopolamine-induced memory impairments in mice. Biol Pharm Bull. 2013;36(1):82-8.

73. Peng Z, Wang H, Zhang R, Chen Y, Xue F, Nie H, Chen Y, Wu D, Wang Y, Wang $H$, Tan Q. Gastrodin ameliorates anxiety-like behaviors and inhibits IL-1beta level and p38 MAPK phosphorylation of hippocampus in the rat model of posttraumatic stressdisorder. Physiol Res. 2013;62(5):537-45.

74. Wang Y, Cao X, Ma H, Tan W, Zhang L, Li Z, Gao Y. Prior stressor exposure delays the recovery of surgery-induced cognitive impairment and prolongs neuroinflammation in aged rats. Brain Res. 2016;1648(Pt A):380-6.
Ready to submit your research? Choose BMC and benefit from:

- fast, convenient online submission

- thorough peer review by experienced researchers in your field

- rapid publication on acceptance

- support for research data, including large and complex data types

- gold Open Access which fosters wider collaboration and increased citations

- maximum visibility for your research: over $100 \mathrm{M}$ website views per year

At BMC, research is always in progress.

Learn more biomedcentral.com/submissions 